\title{
A RATIONALE FOR DEVELOPING FOREIGN-LANGUAGE READING SKILLS 1
}

\section{by Carl James}

\section{Introduction}

In September of last year, United States Education Commissioner James $\mathbf{E}$. Allen urged that the nation set for itself a goal of improving Americans' ability to read in the 1970's with the same energy that put men on the moon in the 1960's. This call for the development of native-language (NL) reading skills should be echoed to those concerned with the teaching of modern foreign languages: After neglecting foreign-language (FL) reading skills for so long through our unbalanced interpretation of audiolingualism, we should redress the balance. A redress is necessary because so many of our students need the foreign-language reading skills in later life; it is attainable, without putting back the clock to 19th century FL teaching methodology, because an effective strategy for developing the reading skill is both harmonious with and an enhancement of the accepted goals of contemporary audiolingualism.

This essay has a dual purpose: 1 ) to provide a working and workable definition of the term foreign-language reading skill; and 2) to describe some mechanical devices of potential usefulness for developing effective foreign language reading skills.

At the outset, we need to explain what we mean when we talk about reading a FL effectively. One must distinguish with deliberate explicitness FL reading from NL reading, or reading in general. FL learning, in all its ramifications, is a substantially different process from NL learning. The differences have recently been tabulated by Cook (1969). It follows that reading in a FL, and teaching someone to read in a FL, must be essentially different from the pracesses in. volved in NL reading. In this respect, it will be illuminating to take a brief look at the history of NL reading instruction.

In the 19th century, in Britain and in America, criteria for evalu. ating reading skill were based on the observable: For a child to

\footnotetext{
1This paper was written while I was supported by a Research Award from the Graduate School to the Department of Language Laboratories, University of Wisconsin-Milwaukee, Milwaukee, Wisconsin. I wish to acknowledge the magnanimity of that institution. I should also like to thank Dr. R. F. Roeming for always finding time to give me the benefit of his insight into problems of foreign language pedagogy. (C. J.)
} 
demonstrate that he could read well. he had to be heard reading well. Reading aloud was equated with reading as such. This attitude is quite understandable today if one reflects that the reading process is an ensemble of mental activities that are not amenable to observation. To employ a concept from communication engineering, the reading process has a "black box" nature. Whatever is going on inside the box (the brain) is not visible; vocalization is necessary to represent the observable (audible) output of that process.

The understandable recourse to vocalization, however, had an unfortunate side-effect. The quality of one's reading was equated with the degree to which the vocal output resembled spontaneous speech. Today it is realized that spontaneous speech differs from prepared speech and even more from written prose. as Wardhaugh (1969 Ch. 4) puts it so succinctly, "Writing is not just speech written down!"

Another consequence of trust in vocalization was even more dam. aging. It was assumed that if the vocalization perfectly resembled spontaneous speech, that was proof that the reader understood what he was reading. At first sight, the logic of such reasoning appears cogent. It was assumed that it would be impossible to assign plausible suprasegmentals (intonations) to stretches of a text unless the reader was understanding the text. To go one step further, it could be claimed that the reader was interpreting the passage, which he could not do, of course, without comprehension. That the reasoning is fallacious has been suggested by the British reading expert, Diack (1965), "There is no necessary connection between the manner in which sentences are read aloud and the degree of understanding them. I may stumble my way through a sentence ... from word to word, my voice giving no indication whatsoever that I am understanding what I am reading; yet it may be my very concentration on the understanding of it all that prevents me from reading fluently." ( $p$. 75). In the light of such a statement, we must doubt the validity of oral reading fluency as a true indicator of reading skill proper.

As is typical of scientific thought, which moves in the dialectic rhythm of thesis-antithesis-synthesis, the 20th century revised the 19 th century conception of the reading process. Today, reading skill is measured along the axes of pace and comprehension, and the optimum pace-comprehension correlation for a text of a given complexity is the goal of most contemporary reading-improvement programs. The necessity of insisting on correlation, rather than relying on pace and comprehension as independent variables. is obvious. Anyone can half-read a text and grasp nothing, and anyone can grasp all, given infinite time for research. Reading pace has itself taken on another dimension, owing to the realization that one can read silently, without 
loss in comprehension, much faster than one can talk, and, of course, much faster than one can read aloud.

This brief interpretation of the history of reading instruction has dealt with NL reading in English. It has already been intimated that FL performance is to be treated differently from NL performance, and now it is proposed that FL reading instruction should not proceed along the lines of historical development followed by NL reading instruction.

The state of affairs referred to as 19th century ideas on reading, is, in the present writer's view, the optimal one to be adopted for present-day FL reading. I do not believe that a FL text should be read silently, and its comprehension ascertained by a series of "questions-on-the-text". The FL reading lesson should consist of reading FL texts out loud at a rate determined by the student's normal speaking speed in the FL. There are reasons for this contention. First, FL reading is never an end in itself, as is leisure reading in the NL. It is unrealistic to tell students to enjoy their FL reading, it is also wasteful of time to allow them to read FL texts unless they can be expected to improve their knowledge of the language from this type of activity. Second, FL reading is seldom an exercise in the acquisition of information or culture per se as it often is in the NL.

FL reading is a means of exposure to the foreign language at all linguistic levels. Through such exposure the learner meets many instances of the grammatical, phonological, semantic, and distributional rules of the FL, some of which he knows explicitly, others of which he can best become aware of through reading. The NL reader already knows the language that the text represents, so for him, it serves no direct linguistic purpose. On the other hand, the FL reader does not know the language yet, or he knows it only imperfectly. That is, the learner has developed certain tentative hypotheses about the structure of the 'target' language; these can best be tested and revised through reference to further representative language data. Reading aloud in the FL ensures a constant scanning of its surface structures, by means of which successive approximations are made in the direction of the information-transmitting deep structure of the FL. In this way it is possible to view rapid NL reading ('skimming') as an information-getting strategy whereby superficial structure is somehow circumvented-partially at least-, the reader gaining direct access to the deep (i.e. semantic) structure of the text. The initial stages of the surface-structure oriented FL reading proposed here will be characterized by a certain semantic vacuousness: at first the student will have difficulty in internalizing the meaning(s) of the text. It is a common finding by foreign language teachers that a stu- 
dent who has just read a passage aloud has virtually no short-term memory of it: I would not be perturbed by this experience.

It is being suggested, therefore, that reading a FL text aloud is a profitable mode of exposure to the foreign language. As such, reading is to some extent comparable with other modes of exposure now traditionally employed in developing the audiolingual skills: watching a film; listening to recordings; seeing a dialogue enacted. But there is an important difference. All of these are stimulus-response activities, to be sure, but with the exception of oral reading, they are passive activities, since they often rely solely on the imitation of a model; even a transformation drill is imitative in this sense. ${ }^{2}$ Moreover, the model is in the same modality as the response-an audible model elicits an audible response. Reading alound is much more active, more demanding and therefore more actively rewarding in the stimulus-response sense of the word than viewing a film, etc. And the stimulus-response modalities are different: First, reading aloud is an act of translation between the visual stimulus and the audible response. (Lane, 1968). Second, reading aloud is also interpretative, since the printed stimulus is relatively neutral, and "says" much less than the oral response is capable of saying. It is the reader's job to supply to the neutral text such features as variations in tempo and voice pitch (intonation), facultative juncture, etc.

Much thought has of late been devoted to the concept of monitoring FL performance. By the term "monitoring" we mean the evaluation of an item of FL behaviour in terms of its conformity to a given model. Monitoring is linked to the behavioristic insistence on knowledge of results, and one of its consequences is the atomization of materials to be learned, with immediate contingent reinforcement of correct responses, as exemplified in programmed learning techniques.

The ingenuity of the language laboratory lies in its provision for monitoring. Dual-track tapes allow the student to match his rendering of a given item with that of a model. The principle of monitoring is not being questioned here; what is being questioned is the naivety with which the principle is applied in FL teaching. The stu, dent in his booth hears from the master track: Heute gehe ich nicht ins Bad, sondern ins Kino. Now he must repeat the utterance. But there are literally dozens of ways to say this sentence, involving all kinds of allophonic, idiolectal, and free variation variables, so why call upon 2My view is diametrically opposed to that of D. A. Lee (1969) who writes, "In the laboratory, the student is mainly involved in active use of the foreign language ... Reading, on the other hand, is mainly an exercise in recognition, ..." Lee seems, however, to be restricting himself here to silent reading. I would still regard even silent reading as involving more activity than most language laboratory drills. 
the student to echo the one arbitrarily selected rendition exemplified on the master track? The demands of imitation can have strange results. There is the "reductio ad absurdum" instance of the male student who resorts to falsetto so as to imitate more truly the highpitched voice of a female on the master track.

Reading aloud never imposes such constraints, since the reader is free to select any vocalizable variant that is consonant with the context. Monitoring now takes on a new dimension in that it is student-centered: the student is expected to evaluate his own vocalization (Clay, 1969). In so doing, he is actively experimenting with the language. If in doubt, he can ask for advice from the instructor, but he will in fact do this less often than might be expected. Provided the text is of a difficulty level commensurate with the student's speaking knowledge of the $\mathrm{FL},{ }^{3}$ he can rely to a large degree on his intuitions: Whether his rendition "sounds right" or not, and now "right" is no longer an all-or-nothing, but a more-or-less affair. That is, the student is involved in the FL, manipulating it like an infant does the NL. He is likely to internalize more of its forms (at all linguistic levels) while he is spared the crippling boredom that audiolingual students are so frequently and intensively forced to endure.

\section{Equipment Application}

This concludes our exegesis of a theory of foreign-language reading. It is now possible to describe a number of mechanical devices which could be utilized to maximize efficiency in FL reading. These devices have two characteristics: a) they are all pacing machines. Some explanation would be in order here as to why I have chosen to recommend pacing hardware from the wide range of alternative types of device available to teachers of NL reading. Some of the minor reasons will emerge in the course of describing these devices, but the central reason is that the goals of FL reading, as adumbrated above, can best be achieved when the student is able to vocalize a FL text at something like normal speaking speed.

To recapitulate: normal speaking speed ensures exposure to the forms of the target language, and self-monitoring can only be accom. plished at natural rates. A further reason for insisting on normal speed hinges on motivation and the avoidance of fatigue. It has been well stated by Reichman (1966): "Unlike reading in one's mother tongue, reading in the foreign language on the intermediate level postpones, sometimes endlessly it seems, the satisfaction of coming to partial and final solutions within the accustomed period of time

3This is the ubiquitous problem of grading. The relative problems of adaptation of extant texts and of the writing of special texts suited to the learner's FL achievement are treated extensively in the literature of Applied Linguistics. Valuable proposals are those of: O'Toole (1967) and Lee (1969). On the notion of the "readability formula" see Spaulding (1956). 
(i.e. vernacular reading time)." Reichman adds: "The student feels condemned, as it were, to an unnaturally slow reading pace." (p. 257).

It is crucial that if reading in a FL is to be bereficial at all, then it must be vocalized reading at a pace consonant with vocalization and with the normal data-processing rate for adults; otherwise, FL reading will not only bore, it will dull the student.

The second feature (b) of the devices proposed is that they rely solely on the visual modality. The reason is that they were designed for use in NL reading training, and, as we have seen, NL reading is mainly silent reading. For FL reading, sound will have to be incorporated when these devices are used. It seems that this is an excellent opportunity to utilize existing language laboratory facilities, with the result that the language laboratory will play a constructive part in FL reading instruction. In this way, FL reading will become truly an audio-visual activity. Suggestions for coupling the language laboratory with the pacing devices will be made passim, as each is described.

One last point needs to be made concerning pace. The pacing machines currently available were conceived for use in NL silent reading, the pace of which far exceeds that of FL oral reading. As a result, the gearing of these devices is generally too rapid for FL reading. As it happens, the slower gears can be used for FL reading, but the ideal situation would be to have duplicate but slower devices manufactured expressly for FL reading instruction. It remains to be ascertained experimentaily what the optimum "shutter" speeds might be for these devices when used in FL reading.

Tachistoscopes

The tachistoscopic principle involves the projected presentation, in a semi-darkened room, of a series of timed exposures, ranging from $1 \frac{1}{2}$ seconds to $1 / 1000$ th of a second in duration. Their use in reading instruction is based on the proposition that much of the activity of seeing needs to be learned, and is not a skill which many individuals develop adequately on their own, merely by frequently being confronted with print. The aim of tachistoscopic training is to develop perceptual accuracy, and it is reasonable to suggest that this is dependent on the student's power of rapid visual discrimination. In NL reading, the child needs to distinguish rapidly and accurately members of the configurational series: dog: bog: gob: god . . . The difficulty of such a task is manifestly greater in FL reading, where the problem of interlingual (or interorthographical) interference arises. The intereference quotient in FL reading is proportional to the degree of isomorphism between FL and NL orthographies. 4 Where the two TThe writer is currently engaged in formulating Contrastive Studies of the Russian and German orthographies with the English. 
languages use different orthographies, such as the Greek or Cyrillic as opposed to the Roman, the problems of perception and discrimination must be tremendous. The reader is referred to Rivers (1968, chapter 9) and Turkevich (1967, Chapter 3) for further statements on this problem.

Tachistoscopic training could constitute part of training the beginner to read a FL. It has two applications at least. 1) When the written language is first introduced, 5 orthographic minimal pairs could be presented tachistoscopically: grand-grande; Krippe-Grippe. dick-dicht; dal'-dal. Students will learn to react to these minimal differences almost instantaneously. At first, the exposure time could be as much as one second, gradually being shortened until the "frustration threshold" is reached by individual students, after which they would drop out and do consolidation work until the training session is over. It is interesting to note that orthographic minimal pairs need not necessarily be phonemic minimal pairs, so tachistoscopic training is not a mere extension of pronunciation drills. English proves the point with such homophonous pairs as pair-pear; seem-seam, etc. In German and Russian, the phenomenon called Auslautsverhärtung provides further cases: when the voiced vs. voiceless plosive opposition is neutralized in word-final position in the direction of the voiceless member, viz: German Tod-tot; Geld-gilt; and Russian rod-rot; pod-pot, etc.

2) At any stage in the course, a new reading passage can be prepared tachistoscopically if "key" words or "new" words are presented in one-half second or one-quarter second exposures. As a result, there will be less stumbling over these words when the reading of the passage is attempted. This is a more sophosticated and more effective way to present new words than the usual vocabulary lists (with glosses) that accompany new texts in the course book.

Using the Tachistoscope in the Language Laboratory

Tachistoscopic training or oral FL reading is best conducted in the language laboratory. The most widely used modern tachistoscope, the TACH-X, 6 is eminently suitable for coordination with the language laboratory, since it operates on a 3-phase schedule, viz: In phase one the short-time exposure is made; in phase two there is a pause for responding; in phase three there is a second, longer exposure of the same frame, for verification and/or reinforcement. Here is how one might utilize the schedule:

In the first trial, a master-track recording of the visual stimulus is synchronized to phase one and three, and the student records his imitation at phase two, thus receiving visual and audible stimuli. SFL "reading readiness" still begs definition.

6Educational Development Laboratories, Inc. 
After 10-15 frames have been practiced thus, the student plays back the total recording, noting the closeness of his vocalization to the master-track model.

In the second trial, the master track voice accompanies phase three only, in which case it performs only a secondary monitoring function, a model against which the student matches his own prior (n. b. not imitative) vocalization.

In the third trial, the only voice recorded, at phases one and three, is the student's. Now he is given a typed list of the 10-15 projected frames, against which at leisure he checks his vocalization by replaying the tape. Some students need more time than others for this, hence the programmed-learning principle of "at leisure" is stressed.

\section{Craig-Reader}

A second device which could be used in the FL reading program is the Craig Reader. It would be employed either in conjunction with, or just after, tachistoscopic training. A box-shaped device, it displays on a TV-like screen a text fed in to it on a $35 \mathrm{~mm}$ film strip. It represents an advance on the tachistoscope (TACH-X) in that it has a greater span-capacity, displaying in timed exposures, and in variablytimed succession, groups of from three to seven words, which might be coterminous with linguistic phrases. The succession is automatic, so the manipulation required by the TACH-X is no longer necessary. One line of text (3-7 words) is illuminated ("exposed") at a time, and the progression is downward, as in normal reading of English, French, German etc. Its speed is variable, so that the reading rate can be adjusted to anything from 150 to 1600 words per minute. For FL reading, as in the case of the Tachistoscope for NL and silent reading the higher reading speeds will not be employable, and some modification will be needed. An additional advantage of this device, issuing from its line-by-line exposure repertoire, is that as soon as the (n th) line is exposed, the immediately preceding (n-lth) line is deexposed: as a result, regression is impossible.

\section{Using the Craig Reader in the Language Laboratory}

The Craig Reader is of portable dimensions, and since it accommodates individualized learning, each student could have his own machine. The price (ca. \$250.) would prohibit supplying enough readers to engage a whole class, so various small-group schedules would have to be worked out. Alternatively, the Craig Reader could be used on a private-study basis, each student being required to spend 30 to 40 minutes working with the machine weekly. 
The machine will fit on the desk of a language laboratory carrel, so the two are physically suited to be used in conjunction. The lan. guage laboratory would also serve the purposes of individualized learning as suggested in the previous paragraph: That is, the student could work without supervision, provided he hands in his recorded reading to the instructor for evaluation.

It should be possible to synchronise-the-device's-rate- of progression through (down)-a text with a master-track recording of the text by a native speaker. Then the student would be able to follow the exposures with his eyes, to an auditory accompaniment from the master track. He would receive signals through two modalities.

At slower speeds, the student would have the opportunity to imitate or to anticipate vocally the master track recording.

The whole passage could be listened to and watched by the student as a preliminary to his own reading aloud of the whole passage.

Another approach would be to allow the student to read "in chorus" with the master track (from the central console), his own voice being recorded on the carrel tape-deck. This approach resembles that of simultaneous conference interpreting with the difference that input and output are both in the FL. It would seem to offer great potential in developing FL reading skills.

\section{Reading Rateometer}

This device is produced by Audio-Visual Research, Inc. It weighs $41 / 2 \mathrm{lbs}$., is the size of a shoe box and thus is portable. It is discussed last since it is the least "artificial" of the devices herein described. In other words, work with the Rateometer most closely resembles the natural reading process: 1) No projection is involved, so it employs no screens, and is used under normal room-illumination conditions, 2) no special techniques (e.g. photography) are used, since the Rateometer is intended for work with normal-format texts-books, pamphlets, typed sheets of text, 3) since no projection is involved, the reading position is the natural one, with the book or sheet flat on the table.

All of these features concerned with the naturalness of our reading habits are important, because a common criticism levelled at the more artificial devices for developing reading skills is this: skills acquired from working with such devices are intrinsic to them; in other words, there is no transfer of training from the artificial to the natural situation. There is probably much truth in this objection to working exclusively with projecting devices. Anyone who decided to use only tachistoscopic techniques in the reading program would probably be disappointed with their ineffectiveness, at least with their uneconomical yield, in terms of the disproportion between time al- 
located and resultant improvement in book reading. It is for this reason that the three devices described here are viewed as a mutually complementary-set of materials. For the same reason it has been emphasized that the three devices are not to be used serially, for example, abandoning the tachistoscope as soon as the Craig Reader is brought into use. Rather, they should be used in an integrated alternating schedule. What the optimum alternation schedule will be is impossible to determine $a$ priori. The number of imponderables and variables involved reduces such prediction to mere guesswork. The function of the Rateometer, however, is principally that of effecting the final transition (at all stages) from artificial to natural reading.

The principle of the Rateometer is simple. With the accuracy of an electric clock, a T-bar moves from the top to the bottom of the printed page, and it is the reader's task to beat the clock, by having read the text before it is concealed by the moving T-bar. The speed of the T-bar's movement is adjustable, and expressible in words per minute (w.p.m.). It is set by adjusting two sliding scales in intersect, the two scales being the Word Count Scale, and the Reading Rate Scale. This computation is rather crude, even for NL reading, in that it fails to take into account the relative difficulties of various texts, or of parts of texts. The rate would have to be varied for FL reading, in terms not only of the words per surface area of paper, but also of 'difficulty. Spaulding's Readability Formula, originally devised for Spanish but applicable to other foreign languages, could be applied at this point. It claims to predict the relative difficulty of reading material "by a simple measure of vocabulary (i.e. frequency, C. J.) and sentence structure" (cf. Spaulding, 1956).

There are three Rateometers available, types A, B, and C. They have three different ranges of speed. It is suggested that for FL reading (aloud) model B would be the most suitable. It was designed for use by slow or remedial readers (NL) and has a range of from 35 w.p.m. to 1000 w.p.m.

\section{Use of the Rateometer in the Language Laboratory}

Individualized learning is again the keynote for using the Rateometer in the language laboratory. The student will compete, not with other students of whose performance he is unaware, but with the rateometer and the master-track recording. On the first run-through, or with a text of considerable difficulty (notwithstanding that preparatory work on unfamiliar and difficult words could have been done using the tachistoscope) the reading rate could be set at quite slow, about 70 w.p.m. First, the student could audit the master-track recording at 70 w.p.m. Then he would return the T-bar to the top of 
the page and try himself to read for one minute at the same speed. "Bleeps" prerecorded on the student tape at one minute intervals will serve as reinforcement according to whether they occur when the student has just completed each 70-word section.

When the student is reading fluently, according to his own estimation, he could record himself for subsequent evaluation by the instructor. Now he can proceed in either of two directions: 1) he can go on to faster speeds, until he achieves a fluent and natural vocalization of the text, or 2) he can concentrate on interpretation. If he chooses to follow the latter course, he will audit readings (at the same speed) by different readers who "interpret" the passage differently." Male and female readers alternate. The effect of all this would be to avoid parrot-imitation (the bane of audiolingualism). Finally, the student would record his own "interpretation", which would be a composite selection from the models he has heard.

It would be mechanically advantageous to couple the stop-start switches of the tape-deck and the Rateometer.

\section{Conclusion}

It has been the purpose of this paper to adumbrate a tentative theory of foreign-language reading instruction which is compatible with contemporary resources of foreign-language teaching technology. The basis of the proposed theory is that FL reading instruction ought to be thoroughly audio-visual. For this reason, silent reading, -which may be the appropriate goal of NL reading instruction, is rejected. Inits place, I have proposed that the audial component be emphasized. Vocalization of a FL text, it is suggested, provides a means of individuated exposure to the target language, while opportunities for selfmonitoring are maximized. The mechanical devices described are those which will_most_advantageously control the visual_input-to-the reading process. Techniques have been suggested to employ these devices to facilltate the achievement of FL reading goals. The language laboratory is seen as a valuable component of the instructional system.

While the author is confident of the potential effectiveness of the proposed system, there are as yet no experimental proofs. Experiments designed to evaluate the assumptions outlined here are ongoing at the time of publication.

Department of Linguistics,

University College of North Wales, BANGOR, Wales, U. $\mathrm{K}$.

7In the Soviet Union, professional actors are commissioned to read short stories, which are used in the Department of Russian for Foreigners of Moscow State University. Such materials would be of great pedagogical value for teachers outside of the Soviet Union. 


\section{References}

Clay, Marie M.: "Reading Errors and Self-Correction Behaviour" British Journal of Educational Psychology. Vol. 39, 1. February 1969.

Cook, Vivian J.: "The Analogy Between First and Second Language Learning." International Review of Applied Linguistics in Language Teaching VIII 3, 1969.

Diack, Hunter.: In Spite of the Alphabet. Ghatto and Windus, London, 1965.

Lane, Harlan L.: "Research on Second-Language Learning" in Rosenberg and Koplin (eds.). Development in Applied Psycholinguistics Research. MacMillan, New York, 1968

Lee, D. A.: "The Language Laboratory and Reading in a Foreign Language." ITL Tijdschrift van het Institute voor Toegepaste Linguistick) Louvain No. 3, 1969.

O'Toole, L. M.: "An Approach to the Problem of Reading at the Intermediate Stage." ATR Journal (Association of Teachers of Russian) 1967.

Reichman, Eberhard: "Motivation and Direction of Reading Assignments on the Intermediate Level." The Modern Language Journal L 5, May, 1966.

Rivers, Wilga M.: Teaching Foreign Language Skills. (Chapter 9,) University of Chicago, 1968.

Sandoval, J. C.: "Techniques for Increasing Reading Speed." Lenguaje y Ciencias, Trujillo, Vol. 29, September, 1968.

Spaulding, Seth.: "A Spanish Readability Formula." The Modern Language Journal. XI, 8, 1956.

Turkevich, Ludmilla M.: Methods of Teaching Russian. (Chapter 3), Van Nostrand Company, 1967.

Wardhaugh, Ronald: Reading: A Linguistic Perspective. Harcourt, Brace and World, 1969. 